\title{
'Who do I turn to if something really bad happens?' Key working and relationship-based practice in residential child care
}

\section{Maria Swan, Stephanie Holt \& Gloria Kirwan}

To cite this article: Maria Swan, Stephanie Holt \& Gloria Kirwan (2018) 'Who do I turn to if something really bad happens?' Key working and relationship-based practice in residential child care, Journal of Social Work Practice, 32:4, 447-461, DOI: 10.1080/02650533.2018.1503161

To link to this article: https://doi.org/10.1080/02650533.2018.1503161

曲 Published online: 19 Nov 2018.

Submit your article to this journal $\pi$

Џll Article views: 213

View Crossmark data $\complement$ 


\title{
'Who do I turn to if something really bad happens?' Key working and relationship-based practice in residential child care
}

\author{
Maria Swan, Stephanie Holt and Gloria Kirwan \\ Trinity College Dublin, Ireland
}

\begin{abstract}
This article explores the psychodynamics of relationship-based practice from the perspective of young people in residential care. This research involved qualitative semi-structured interviews with 10 care leavers, aged 18-24 years, who had been in residential care in Ireland. Drawing selectively from that research, this article reports their views and experiences of key-working and how relationship-based practice acted as a reparative method within their experiences of care and aftercare. Similar to previous research, this study underscores the necessity to ensure that children in care are cared for and supported by a trusted adult. In addition, based on this study, the role of a key worker appears capable of providing this ideal type of supportive relationship. It also highlights the importance of the care system working to provide consistency and support for the young people and confirms the importance of relationships with trusted adults, such as key workers.
\end{abstract}

\section{KEYWORDS}

Relationship-based practice; young care leavers; continuity; key worker; key working

\section{Introduction}

It has long been apparent that children at the point of leaving state care can be at a disadvantage compared with their counterparts coming from a traditional family setting (O’Higgins, Sebba, \& Luke, 2015). Research shows that there are higher recorded rates of homelessness, addiction issues, unemployment and mental health problems (Stein, 2006) amongst this cohort. Although previous research has looked into various factors that influence the outcomes for cared for children, few reported studies have explored the psychodynamics of relationship-based practice from the perspective of young people in residential care. Drawing selectively from research with young adult care leavers, this article reports their views and experiences of key working and how relationship-based practice acted as a reparative influence within their experiences of care and aftercare. Many young people find the transition from adolescence to adulthood complex and challenging, even with support from family and friends (Stein, 2006). However, young people in and leaving care often have poor relationships with their family and little support during this transitionary time (Stein, 2006). In addition to processing the impact of having lived in the 'artificial environment' that is a care 
placement (Mullan, McAlister, Rollock, \& Fitzsimons, 2007), this study reveals how leaving this 'artificial environment' abruptly at the age of 18 can be a difficult experience for young people. Research participants regarded relationship continuity with key workers as an important informal support during their transition into the 'real world', a period when they had few other forms of support (Holt \& Kirwan, 2012).

There is a growing literature on care-leavers and their outcomes, in the Irish context (Daly, 2012) and internationally (Bullock, Courtney, Parker, Sinclair, \& Thoburn, 2006). However, with the exception of a small number of studies, there is a dearth of research on relationship-based key working with children in care; particularly, the research, which amplifies the voice of young adult care leavers on this issue (Cahill, Holt, \& Kirwan, 2016; Morrison, 2015). Responding to that knowledge gap, this study involved qualitative semi-structured interviews with 10 care leavers, aged 18-24 years, who had been in care in Ireland. Thematic analysis highlighted the importance of relationship-based practice for promoting felt-security and helping these young people to move positively towards independent living. This article also highlights the potential obstacles to effective key working relationships. The benefit for young people of relationship continuity with key workers emerged as a finding in this study. We begin by outlining the Irish context, where this research study was conducted, before moving to present a selective review of the related literature.

\section{The Irish context}

Similar to the experience of many developed countries, the Irish care system for children has undergone significant change from the 1970s onwards. Although residential care was once the preferred form of state provision for cared-for children, foster care is now regarded as better suited to meet the needs of the majority of children, who require out-of -home care (Gilligan, 2009). The shift away from residential care, historically provided in large, warehouse-style institutions, has been influenced by a number of factors including the international practice of deinstitutionalisation, and a shift in favour of the provision of alternative family placements (either kinship or foster placements).

The policy shift towards deinstitutionalisation in child care services found expression in the Report of the Committee of Enquiry into Reformatory and Industrial School Systems (1970), generally referred to as The Kennedy Report. The Kennedy Report viewed reliance on residential care as outmoded and no longer compatible with contemporary childcare practice, except in cases where other care options are unavailable or in order to keep sibling groups together. The Report called for residential care to be provided in small, family-type units staffed by properly trained workers. Of relevance to the present study, the Report also devoted a chapter to the topic of aftercare, where it highlighted the value of planned transitions for young people leaving care.

Subsequently, the Irish care system evolved to reflect many of the Kennedy Report recommendations. Nowadays, the majority of children living in alternative care are placed in fostering or kinship type placements. However, demand for residential care continues to exist for a minority of children within the care system. Residential care continues as the option of choice in situations, wherein sibling groups would be otherwise separated or a young person has particular needs best met, for a period of time at least, within a residential setting as opposed to a foster care environment. Some 
young people, for example, will have experienced abusive or traumatic events in their family of origin and may need the assistance of specialist services to recover and prepare for entry into foster care. Winter's (2010) research with young children in care reveals the extent to which young children can report awareness of the levels of risk they experienced in their home environments and how they had tried to develop coping mechanisms to deal with the impact of such experiences. Bruskas and Tessin (2013) report the further negative impact on young people of multiple foster placement breakdowns and Dixon (Dixon, 2008b, p. 86) echoes this point regarding the deleterious effect of unplanned change in a young person's life or placement instability. Therefore, placement stability is central to successful outcomes for young people who enter the care system; in addition, although foster care is generally regarded as the ideal location for such care (Harden, 2004), residential care can provide the necessary stability for a period of time in a young person's life whilst they work through the impact of past negative family experiences. The importance of suitably skilled staff in such settings is, therefore, essential (Cameron \& Boddy, 2008). The current residential facilities in Ireland, reflecting the recommendations of the Kennedy Report, are smallscale, community-based care settings, which approximate a typical family environment. The Department of Children and Youth Affairs (Department of Children and Youth Affairs, 2016, p. 212) reported that 5\% $(n=351)$ of children in care in 2015 were placed in residential care facilities whilst the vast majority of children in care were living either with foster families or in extended family placements. These figures illustrate a reversal of the pattern recorded in the mid-twentieth century when the bulk of children cared for by the state were placed in some form of residential setting (O'Sullivan, 2014).

Despite the general move away from residential care, the standards of provision in this sector reflect a growing understanding of the benefits for children of being cared for by staff who have received relevant training and supervision (Williams \& Lawlor, 2001). The statutory registration of social workers, with that of social care workers in the pipeline, was given a legal footing under the Health and Social Care Professionals Act 2005; thus, adding another strand of standard-setting and accountability within the provision of child welfare services, including residential care for children.

Recent legislation (the Child Care (Amendment) Act 2015) has placed a statutory duty on the relevant authority (in this instance the Child and Family Agency) to prepare an aftercare plan for any eligible person who is exiting the child care system, including those who have been cared for in residential care. It is important to note that some of the study participants who took part in the present study had transitioned out of care before the statutory requirement for an aftercare plan became operational.

In summary, the most recent history of service provision to cared-for children in the Irish context has followed the international trend of an increased use of family placements and the shrinking of residential care provision. Nonetheless, the figures indicate that annually over 300 children in state care are cared for in residential settings. The importance of understanding the experiences of this group remains current and relevant for those involved in working directly with this group, planning services for them or delivering training to relevant staff. The study reported here recognises the need to amplify the views of residential care leavers regarding their experiences of residential care, in general, and key working, in particular. Before the study findings are presented, the next section reviews the literature relevant to the present study. 


\section{Literature review}

The study reported here aimed to capture the views of young graduates of the residential care system regarding the role of key workers they had encountered during their experience in out of home care. The literature review presented here highlights the role of relationships in general for young people in care, and the research to date on key working in that context.

\section{The importance of relationships for looked after children}

As children embark on the journey through childhood into adolescence and on to adulthood, the majority experience love, support and stability that facilitate them to prosper into independent, confident adults (Public Interest Law Alliance \& Barnardos, 2012), with relationships often viewed as fundamental in enabling positive life changes to occur (Burnett \& McNeill, 2005).

In contemporary society, primarily due to economic constraints, many young people stay in the family home until they are in their mid-twenties and have a strong network of support amongst their family and friends (Public Interest Law Alliance \& Barnardos, 2012). However, for young people, who have been raised in state care, their journey from childhood to adulthood may not have been so well supported (Dixon, 2008a). There is further empirical evidence to attest that failure to prepare and support these young people for the experience of the world outside of care may result in exposure to social exclusion, including experiences of homelessness, addiction, criminality, prostitution, early parenthood, poverty, mental health issues and even premature death (Stein, 2015). Greeson, Thompson, Ali and Wenger's (2015) exploratory research found that the enduring presence of at least one caring, committed adult in the life of a young person may mitigate against negative outcomes.

The qualities and skills of relationship-building possessed by care staff, and key workers in particular, have been deemed fundamental in engaging with young people in care (McKellar \& Kendrick, 2013). Kohlsteadt (2010) discusses the transformative potential of positive relationships between young people in care and their carers. According to De Boer and Coady (2007), characteristics identified as integral for positive relationships between service users and service providers more broadly, include trust, warmth, respect, communication and collaboration. However, questions remain about the outcomes for young adult care leavers who reside in residential units with a continually changing staff rota, different shift times, relief workers and a conveyor belt of different social workers. The evidence further suggests that young people can find it challenging to manage the residential worker's 'dual remit of care and control' (Barry, Moodie, Morrison, \& Cruickshank, 2008, p. 60). Furthermore, residential staff's ability to spend time building a relationship with a vulnerable young person can be constrained by increasing bureaucratic demands (Howard, 2012).

From a care leaver's perspective, Morrison's (2015) recent reflection on her care experience emphasises the importance of nurturing relationships where the child or young person feels safe, understood and valued (Turney, 2010, p. 133). The continuity of these relationships is especially valuable in the transition from care to adult life (Schofield, Larsson, \& Ward, 2017; Stein, 2015). De Boer and Coady (2007) 
associate outcomes for services users with the quality of the worker/service user relationship.

\section{The value of a secure base in cared-for relationships}

The evidence highlights the influential role of a child's secure base on all other domains of their development, including education, friendships and social competencies (Bell \& Romano, 2014). Research conducted in a secure centre indicates that well-adjusted adolescents more often used the relationship with care workers as a secure base and less often avoided contact with their care worker (Zegers, Schuengel, Van IJzendoorn, \& Janssens, 2006).

However, for children in care, forming secure attachments can be challenging due to traumatic attachment histories (Schofield \& Beek, 2005). Fundamental to supporting positive outcomes for children in care is the formation of healthy attachments with their caregivers (Stein, 2015).

Cashmore and Paxman's (2006) research illustrates how felt security in relationships can be a fundamental bridge in helping young people mediate the experience of separation from their family of origin. The role of the key worker in fostering this felt security through the medium of relationship-based practice is, therefore, an obvious consideration. However, to date, there has been a dearth of research with young care leavers regarding their views on the relationship-based approach to working with children in care and the role of the key worker (Holt \& Kirwan, 2012). However, it has been acknowledged in more general terms that 'the downplaying of relationship has led to serious gaps in practice' (Turney, 2012, p. 150).

\section{The key worker role in relationship-based practice}

The concept of key working can differ depending on the environment. Mallinson (1995, p.2) describes this concept as, 'a system for providing individualised social care through named persons'. Mallinson's (1995) research, albeit in a different care setting, highlighted the important role key workers play in providing practical care, assessment, advocating, counselling, recording and arranging activities. Key workers also play an important role in coordinating the service user's care. This often means that the designated key worker is the 'go-to' for all other professionals involved in the young person's life. As Mason (2012, p. 368) stated, 'the relationship has long been considered the "bedrock" of social work practice with children and families'; in addition, it is suggested here, it also should be for key workers and key workees. This 'throughcare' approach, where the key worker is involved during and after the young person's journey in care, assists in providing the young person with a secure base to support their transition into independent living. This emphasises the stabilising role of the key worker in 'looked after' children's lives.

Amy, Claire, Jordan and Glen (2010) assert that the key worker/key workee relationship may, for some children and young people, be the only constant 'positive' relationship that a young person in care has experienced throughout their whole life. Kohlsteadt's (2010) descriptive article, on the developmental/relational approach to residential care for children, discusses how the relationship is often central to healing trauma experienced by the young person. The role of a key worker in the looked after 
child's life, when it works well, can, therefore, provide that child with an important relational experience, with the key worker providing 'the patterned, repetitive structure, care, fun and connection as well as confrontation, saying no, and being with the child in pain that allows the child to open himself/herself to a world of trust' (Kohlstaedt, 2010, p. 49). This present study captures the views of young people as graduates of the Irish residential care system on how well the key working system is currently performing this role. As Winter (2015) suggests, the key worker has the ability to enhance the care experience of a young person in care and it is through the relationship they build with that young person that much of that success will be mediated.

In summary, the literature reviewed for this study has highlighted the importance of the key worker role in a relationship-based approach to working with young people in care. The literature indicates that this role is integral in developing and assisting young adults to feel they have a secure base from which they can move towards independence. How good or beneficial in practice the role of a key worker is will now be explored through the voice of young people who have left care.

\section{Methodology}

The research methodology adopted to conduct this study was influenced by a phenomenological approach in conjunction with social constructionist theory (Alston \& Bowles, 2013). Phenomenological epistemology is concerned with understanding people's everyday experience of reality in an attempt to gain an understanding of the phenomenon in question (Braun \& Clarke, 2006). Social constructionism marries with phenomenology in its stance that knowledge can be gained by examining interchanges in social, cultural and historical contexts (Payne, 2005, p. 58). This methodological perspective suitably frames the research approach for this study, as it is investigating young people's experiences of key working in the social context of residential care.

As a prerequisite to conducting this study, full ethical approval was sought from and granted by the Research Ethics Approval Committee of the School of Social Work and Social Policy, Trinity College Dublin. Participant recruitment and voluntary consent were important ethical issues requiring consideration in this study. Following ethical approval, a nonprobability cluster sampling procedure (Daniel, 2012) was used to ensure that young adult care-leavers met specific criteria that fitted with the purposes of the research (Greeson et al., 2015). The inclusion criteria required that all participants were over 18 -years-old and had residential care experience. During the recruitment process, the possibility of causing distress and eliciting painful memories for the potential participants was carefully considered and the principles of nonmaleficence and beneficence were to the fore of the ethical consideration. To this end, the exclusion criteria emphasised that all potential interviewees who were not emotionally and physically stable at the time of the interview would not be invited to participate. In identifying potential participants, Residential Care Managers, acting as gatekeepers, applied the inclusion and exclusion criteria; in addition, they acted as a postinterview source of support to the participants when necessary. Informal follow-up was conducted with gatekeepers, post interviews, to confirm that the respondents did not present as distressed following the interview process.

As stated earlier, this article reports on a project initiated in 2011 (Holt \& Kirwan, 2012) concerned with exploring key working and relationship-based approaches in 
residential child care practice, from the perspectives of residential social care workers and young care leavers. The first phase of this study accessed participants through the National Residential Child Care Managers Forum, the National AfterCare Workers Forum and a third national organisation, which advocates on behalf of young people either living within or graduated from the Irish care system.

In addition to 20 key work staff, four young people were accessed in the first phase through these gate-keeping sources and participated in one group and one individual interview. Although a number of other young people indicated their interest in participating in the research, they did not present themselves for scheduled and subsequently rescheduled interviews. A number of writers have highlighted the general challenges of conducting research with young people (Water, 2018) and the particular challenges of gaining access to and recruiting young people living in residential homes (Kendrick, Steckley, \& Lerpiniere, 2008). Although the sample in the present study involved young people who had graduated from care and were no longer living in residential facilities, many of the same obstacles were still at play, including the necessary practices of recruiting through intermediary gatekeepers. It is also possible that certain factors, such as a reluctance to discuss painful life events, explain the low numbers who actually engaged in the study (Daly, 2012).

The second phase of data collection, in 2015, involved five interviews with six young care leavers. This built on the earlier data set and addressed the low number of care leavers recruited in 2012. These six young care leavers comprised one female and five male participants, and were recruited through the first author's previous contact with an aftercare unit in Dublin. There were four individual interviews with one female and three males; and one joint interview with two males.

The present article reports solely on the analysis of the care leavers' data set comprising of the interview data from phase one (2011) and phase two (2015) of this study. The profile of the 10 participating young people includes seven male and three female care leavers between the ages of 18-24 years at the time of interview. Their care careers spanned between three and 13 years in state care, predominantly but not exclusively within the residential care sector, involving between one residential care setting experience to multiple moves and experiences. One interviewee recalled up to 20 moves; however, precise recollection of the details of all the transitions got lost over the period of time. All the participants had most recently experienced care in the residential sector. All qualitative interviews were audio recorded with consent, transcribed and coded by the researchers. The semi-structured interviews allowed for flexibility and freedom for interviewees to digress on unasked topics, which often provided rich and profound data.

A thematic analysis was employed as a means to interpret the information. Thematic analysis focuses on identifiable themes and patterns of living and/or behaviour within data. It is an analysis that emphasises what is said rather than how it is said (Bryman, 2004, p. 412). In addition, thematic analysis is associated with social constructionist methods. It examines the ways in which events, realities, meanings and experiences are the effects of a range of discourses operating within society. Therefore, thematic analysis can be a method that works to reflect reality and de-layer the surface of 'reality' (Braun \& Clarke, 2006). Limitations to the study were mainly associated with the small number of participants and the unequal balance in numbers between male and female participants. 


\section{Findings and discussion}

This section thematically presents three key findings that emerged organically throughout the interview process as they were the topics the participants repeatedly discussed and referred to throughout the interviews. Despite the participants coming from a range of backgrounds and care experiences, the three highlighted themes that appeared portrayed a commonality and unifying lived experience by all interviewees. These themes include: first, the importance of a home-like environment; second, the positive elements of the key working relationship; and, finally, the importance of key working relationships enduring into the aftercare period.

\section{The importance of a home-like environment for young people in out-of-home care $^{1}$}

Echoing the wider literature, a common theme for all participants was their negative experiences of relationships at home prior to entering care (Gaskell, 2009). For many of the participants, their family relationships did not improve after they entered into care, as Paul reflects:

Yeah...well, me family never really had much to do with me when I was in here [the residential unit] (Paul)

Indeed, for many participants, their residential unit was the closest experience they had to a traditional concept of a home. This next quote from Declan identified what he perceives as the important elements of the concept of 'home':

I haven't had a good upbringing. And when I moved to [name of residential unit], it was actually $[\ldots]$ it was a house [...] it was a home. I'd come home with me dinner on the table, knowing that I didn't have to come home to drama, that people cared about me, that I knew I was safe and I was looked after. (Declan)

Declan's reference above to the importance he attached to 'having people who cared' about him was echoed across all the interviews. For example, in response to being asked if he considered his residential unit his home, Paul responded:

Oh definitely! It's the happiest place I've ever been in my life. I never liked living at home.

It never worked. That's why I went into care as well. (Paul)

Paul further asserted that he attributed this sense of home '100\%' to the care staff working there. In creating that sense of 'home', participants spoke of things one would consider to be normal household activities, such as washing up and celebrating important events. This appeared to create a sense of belonging and routine, which are the activities identified as paramount to successful outcomes for children; particularly, those who have experiences of being in care (Halpenny, Keogh, \& Gilligan, 2002). Integral to a sense of home was the key worker relationship, considered significant by all participants. Each participant attributed their sense of belonging within their residential care setting to the relationship they had with their key worker. Emerging from the data analysis is a clear connection between the experience of positive relationships with key working staff and feelings of security, supporting the existing evidence, which indicates that staff working in 
cared environments is at the core of enhancing relationship-based practice (Turney, 2010) and creating that sense of home. The next section explores that further.

\section{The importance of relationships}

Reflecting on the importance of their relationships with their key workers, all of the participants highlighted certain approaches the key workers employed, which enhanced rapport and relationship-building. Humour and the worker's approachability were two characteristics of key workers valued by the participants and viewed as important by them in contributing to the development of trust in the residential environment. This is explained by Paul:

Yeah, someone who is easy to talk to and knows the craic. ${ }^{2}$ And you can talk to them, you know what I mean? Not someone who is like, always trying to sort something out, who is annoying to talk to, you know what I mean? (Paul)

Participants in this present study emphasised the importance of their key workers being present for them when they required support, as Declan explains in this next quote:

If I had to tell him [Karl, his keyworker] something that was serious or something, he would be there for me but I've always told him everything and I've always trusted him with everything.... Karl and Cheryl wouldn't be working but they would actually come in on their day off and bring me out for the day. (Declan)

For the young people in this study, the ability to build trusting relationships with young people in their care was viewed by the participants as a key feature of the key worker's role. This and other aspects of that role are expanded on in the next section.

\section{Key aspects of the key working experience}

The findings of this study highlighted many key aspects of the key working relationship that participants commented on positively. For example, the key working relationship was viewed by participants along a caring spectrum, albeit with different descriptions. Although, the care staff role includes elements of care and control (Barry et al., 2008), the young people in this study identified as positive the consistency and support, which they found within their relationships with their key workers and which may have been absent for many of them in their biological family situation. Amy gives voice to this experience of care and control, stating: 'they just, they were just the right balance of protective and kinda of supportive....they encouraged me to be myself.

Echoing Holt and Kirwan's (2012) assertion regarding the importance of key workers establishing a secure relational base with young people in their care, Paul's next quote highlights the value he placed on the support he received, stating that his key worker was 'just someone there to give you support. If you need to talk to anyone, it would be them'.

In a similar vein, the notion of 'felt security' (Cashmore \& Paxman, 2006) was highlighted by participants, including Declan who is quoted below describing the caring nature of the key worker's role: 
Em...I wouldn't say it's a Mammy or Daddy role...It would just be...you know, someone that's there who will look after you, that they're there for when you need them and you can rely on them. (Declan)

Negative aspects of the key working experience also emerged from the findings. The changeover of staff (the roster system) presented as an issue for some participants who cited difficulties talking to other staff members about their issues, highlighting a clear challenge of the key working role, as Lisa explains:

It was hard like when you're trying like if your keyworker is not in or is not on shift or whatever like and then you really need to talk to somebody. (Lisa)

Similarly, constant staff changes or the employment of relief workers can impact on staff-child relationships in residential care. Michael expands on the negative impact of staff turnover in this next quote:

There are loads of people out there who need keyworkers. I don't know, like, its kinda like a social worker, they just keep changing. They are just gone and you just have to deal with it. (Michael)

Holt and Kirwan's (2012) research acknowledged the importance of the key working role in providing continuity and a sense of belonging for the young people, which is linked to the emphasis of second chance secure base that Graham (2006) refers to. A similar point is made by one of the participants, Michael:

I think you need one [trusted adult] that stays with you for the whole time, till you're gone. Even after. Like, I think everyone, I think people especially in care because there are people out there who don't have anybody, I think that you need to have someone there that you can always go back to, you know what I mean? So I definitely think that you should have someone you can go back to till 22 or whatever would be a better idea.

This present research highlights the importance of relationship continuity and the challenges that high staff turnover can present to that important process. Although this is difficult to solve, the message from this study is that where relationships between young people and key workers have been established and are working well, every effort should be made to maintain rather than rupture those relationships. The next section focuses on this.

\section{Relationship continuity}

Echoing Schofield et al.'s (2017) assertion that the continuity of relationships is especially valuable in the transition from care to adult life, this study also confirms that the continuity of relationships young people form with key staff offers an important source of support during their transition out of care and even after young people have left care.

For many participants in this present research, the relationship with their key workers continued after the young people left care and transitioned into independent living, highlighting the capacity for that care setting to facilitate young people to have positive relationships with key workers and indeed the importance of those relationships during their period in care and in their life after care. It is significant that all the participants in this present research were over the age of 18 and the majority still 
sustained supportive relationships with staff from their residential units. Following their initial departure from residential care, six out of the 10 participants advised that they were contacted via telephone by their previous key workers to 'check-in'. Furthermore, a minority cited being able to return for 'sleep-overs' or to attend traditional 'family events', such as Christmas, Easter and birthdays, as Amy explains:

And when I moved out, I was able to go back. So I only part-time moved out, I guess. (Amy)

Stein's (2006, p. 274) notion of 'accelerated and compressed transitions' also emerged in this present research, with participants reflecting that whilst staff tried to assist them in developing independent living skills, the young people themselves reported that they were not always ready to learn such skills. Jonathon recalls this process:

I learnt the hard way a few weeks in a row. I just spent my money in the first few days and realised that I had no other money for the rest of the days. It's a good one [lesson] but it's tougher and tougher. And I say to this lad here [points to Fionn] open a savings account and just put money away and just don't touch it. (Jonathon)

In the context of the challenges encountered by participants as they transitioned out of care, the young people indicated that they felt reassured by the knowledge that they could return when necessary to their residential unit, their 'home', their secure base, for support. Drawing on Morrison's (2015) experience as a care leaver, those warm working relationships are especially valuable in the transition to after care; particularly, when we reflect on the absence of that relational base in the young person's family of origin as Jonathon poignantly considers:

I can't trust my family, so it's kinda like, fuck, who do I turn to if something really bad happens? (Jonathon)

Drawing this section to a close, this present research has highlighted that the relationship between key worker and young person could be construed as the 'active ingredient' (Li \& Julian, 2012) in determining the quality of experience for young people, during their period in care and in the period after they formally leave the care system. The findings show that young care leavers' experiences of key working relationships, as part of a wider network of relationships with their carers in residential child care, can enhance their sense of a secure base and their ability to transition into independent adulthood. The significant role that key workers can play in a young person's life is captured in this final word from Declan who suggests that:

Only for them [staff and keyworkers], I know this sounds horrible and all, but only for them, I'd be dead. (Declan)

\section{Conclusion and recommendations}

The aim of this research was to look at the role of key working in residential units and how young care leavers experience key working relationships as they move through and out of the residential care system. This article focused on the viewpoints of 10 young 
care leavers and their experiences of the key working system in residential units, with particular reference to the relationship between themselves and their key worker(s).

The study found that the participants interviewed as part of this study experienced the key working system positively. They reported positively on the relationships they built with key workers, relationships which they viewed as enhancing and developing their sense of security and their ability to move towards independence when they arrived at the point of leaving care. Key aspects that were important in this relationship were certain characteristics of a key worker, such as reliability, honesty and trust. As asserted by Stein (2015), the continuity of relationships with key workers was also highlighted by the participants as well as the enduring nature of those relationships. Being able to call on the support of a key worker in the period after leaving care was viewed as highly important by many of the interviewees.

Echoing previous research on care leavers' experiences of key working (Amy et al., 2010; Morrison, 2015) this study underscores the necessity to ensure that all children in care are cared for and supported by at least one trusted adult figure, and based on this study, the role of a key worker appears capable of providing the ideal type of relationship in which this support can be delivered. It also highlights the importance of the care system working to provide the consistency and support that may have been previously lacking for a young person within their family of origin environment (Gaskell, 2009). The importance attached to key working relationships by young people in this study was captured in the reflection by one of the participants who suggested that for them, their key worker was the main person they would 'turn to if something really bad happens'. This sums up the importance of relationships for young people whose difficult and disrupted start in life has left them with relationship gaps with trusted adults. This study has demonstrated the role that key working can play in helping fill that relational void.

\section{Notes}

1. All participant names and identifiable information has been changed to protect their confidentiality.

2. The term 'knows the craic' (pronounced 'crack') means someone who knows about the other person's experience in a specific situation.

\section{Disclosure statement}

No potential conflict of interest was reported by the authors.

\section{Funding}

This research project was supported with a grant from the Arts, Humanities and Social Sciences Benefactions Fund, Trinity College Dublin. 


\section{Notes on contributors}

Maria Swan graduated from Trinity College Dublin with a Masters in Social Work in 2013 and now works as a mental health social worker working with the homeless population in Dublin, Ireland.

Stephanie Holt, $\mathrm{PhD}$, is an Associate Professor in the School of Social Work \& Social Policy, Trinity College Dublin, Ireland.

Gloria Kirwan is Assistant Professor of Social Work in the School of Social Work and Social Policy, Trinity College Dublin, Ireland.

\section{References}

Alston, M., \& Bowles, W. (2013). Research for social workers: An introduction to methods. London: Routledge.

Amy, Claire, Jordan \& Glen (2010). Service user perspectives on the "ethically good practitioner". Ethics and Social Welfare, 4(1), 91-97.

Barry, M., Moodie, K., Morrison, E., \& Cruickshank, C. A. 2008. This isn't the road I want to go down: Young people's experiences of secure care. Glasgow: University of Strathclyde. Retrieved from https://strathprints.strath.ac.uk/20234/1/strathprints020234.pdf

Bell, T., \& Romano, E. (2014). Child resilience in out-of-home care: Child welfare worker perspectives. Children and Youth Services Review, 48, 49-59.

Braun, V., \& Clarke, V. (2006). Using thematic analysis in psychology. Qualitative Research in Psychology, 3(2), 77-101.

Bruskas, D., \& Tessin, D. H. (2013). Adverse childhood experiences and psychosocial well-being of women who were in foster care as children. Nursing Research \& Practice, 17(3), 131-141.

Bryman, A. (2004). Social research methods (2nd ed.). Oxford: Oxford University Press.

Bullock, R., Courtney, M. E., Parker, R., Sinclair, I., \& Thoburn, J. (2006). Can the corporate state parent? Children and Youth Services Review, 28(11), 1344-1358.

Burnett, R., \& McNeill, F. (2005). The place of the officer-Offender relationship in assisting offenders to desist from crime. Probation Journal, 52(3), 247-268.

Cahill, O., Holt, S., \& Kirwan, G. (2016). Keyworking in residential child care: Lessons from research. Children and Youth Services Review, 65, 216-223.

Cameron, C., \& Boddy, J. (2008). Staffing, training and recruitment: Outcomes for young people in residential care in three countries. In A. Kendrick (Ed.), Residential child care: Prospects and challenges (pp. 210-225). London: Jessica Kingsley Publishers.

Cashmore, J., \& Paxman, M. (2006). Predicting after-care outcomes: The importance of 'felt' security. Child and Family Social Work, 11(3), 232-241.

Daly, F. (2012). What do young people need when they leave care? Views of care-leavers and after-care Workers in North Dublin. Child Care in Practice, 18(4), 309-324.

Daniel, J. (2012). Sampling essentials. Thousand Oaks, CA: Sage Publications.

De Boer, C., \& Coady, N. (2007). Good helping relationships in child welfare: Learning from stories of success. Child and Family Social Work, 12, 32-42.

Department of Children and Youth Affairs. (2016). State of the nation's children: Ireland 2016. Dublin: DCYA.

Dixon, J. (2008a). Young people leaving care: Health, well-being and outcomes. Child \& Family Social Work, 13(2), 207-217.

Dixon, J. (2008b). Young people leaving residential care: Experiences and outcomes. In A. Kendrick (Ed.), Residential child care: Prospects and challenges (pp. 76-89). London: Jessica Kingsley Publishers.

Gaskell, C. (2009). 'If the social worker had called at least it would show they care': Young care leavers' perspectives on the importance of care. Children \& Society, 24, 136-147.

Gilligan, R. (2009). The "public child" and the reluctant state? Eire-Ireland, 44(1/2), 265-290. 
Graham, G. (2006). Attachment theory and wellbeing for the young person in residential care: The provision of a second chance secure base for the child in crisis. Relational Child and Youth Care Practice, 19(1), 23-34.

Greeson, J., Thompson, A. E., Ali, S., \& Wenger, R. S. (2015). It's good to know that you got somebody that's not going anywhere: Attitudes and beliefs of older youth in foster care about child welfare-based natural mentoring. Children and Youth Services Review, 48, 140-149.

Halpenny, A., Keogh, A., \& Gilligan, R. (2002). 'A place for children? Children in families living in emergency accommodation: The perspectives of children, parents and professionals'. Homeless Agency Report Paper 14. Dublin: Children's Research Centre, Trinity College Dublin. Retrieved from https://arrow.dit.ie/cgi/viewcontent.cgi?referer=https://www.google. co.uk/\&httpsredir $=1$ \&article $=1017 \&$ context=aaschsslrep

Harden, B. J. (2004). Safety and stability for foster children: A developmental perspective. The Future of Children, 14(1), 30-47.

Health and Social Care Professionals Act 2005. Dublin: Government Publications.

Holt, S., \& Kirwan, G. (2012). The key to successful transitions for young people leaving residential child care: The role of the Keyworker. Child in Care Practice, 18(4), 371-392.

Howard, N. (2012). The ryan report (2009). A practitioner's perspective on implications for residential child care. Irish Journal of Applied Social Studies, 12(1), 38-48.

Kendrick, A., Steckley, L., \& Lerpiniere, J. (2008). Ethical issues, research and vulnerability: Gaining the views of children and young people in residential care. Children's Geographies, 6 (1), 79-93.

Kohlstaedt, E. (2010). What is harmed by relationship can be healed by relationship: A developmental/relational approach to residential treatment for young children. Scottish Journal for Residential Child Care, 9(1), 44-53.

Li, J., \& Julian, M. M. (2012). Developmental relationships as the active ingredient: A unifying working hypothesis of "what works" across intervention settings. American Journal of Orthopsychiatry, 82(2), 157-166.

Mallinson, I. (1995). Keyworking: An examination of a method of individualising care for older people in residential units. Aldershot, UK: Avebury.

Mason, C. (2012). Social work the 'art of relationship': Parents' perspectives on intensive family support project. Child and Family Social Work, 17(3), 368-377.

McKellar, A., \& Kendrick, A. (2013). Keyworking and the quality of relationships in secure accommodation. Scottish Journal of Residential Care, 12(1), 46-57.

Morrison, S. (2015). In care, aftercare and caring for those in care: My successful care journey. Child Care in Practice, 22(2), 113-127.

Mullan, C., McAlister, S., Rollock, F., \& Fitzsimons, L. (2007). Care just changes your life: Factors impacting on the mental health of children and young people with experiences of care in Northern Ireland. Child Care in Practice, 13(4), 417-434.

O'Higgins, A., Sebba, J., \& Luke, N. (2015). What is the relationship between being in care and the educational outcomes of children? An international systematic review. Oxford: Rees Centre.

O’Sullivan, E. (2014). Child welfare services 1979-1980: From the Kennedy committee to the task force. In M. Luddy \& J. M. Smith (Eds.), Children, childhood and Irish society, 1500 to the present. Dublin: Four Courts Press.

Payne, M. (2005). Modern social work theory (3rd ed.). Palgrave: Macmillan.

Public Interest Law Alliance \& Barnardos. (2012). Moving on: Aftercare provision in Ireland. Retrieved from https://www.barnardos.ie/assets/files/Advocacy/2012AftercareSeminar/ Barnardos\%20and\%20PILA\%20Aftercare\%20Paper\%202012.pdf

Report of the Committee of Enquiry into Reformatory and Industrial School Systems (1970). Dublin: Stationery Office.

Schofield, G., \& Beek, M. (2005). Providing a secure base: Parenting children in long-term family foster care. Attachment and Human Development, 7(1), 3-26.

Schofield, G., Larsson, B., \& Ward, E. (2017). Risk, resilience and identity construction in the life narratives of young people leaving residential care. Child and Family Social Work, 22(2), 782-791. 
Stein, M. (2006). Research review: Young people leaving care. Child \& Family Social Work, 11, 273-279.

Stein, M. (2015). Supportive pathways for young people leaving care: Lessons learned from four decades of research. In J. K. Whittaker, J. F. Del Valle, \& L. Holmes (Eds.), Therapeutic residential care for children and youth. London: Jessica Kingsley.

Turney, D. (2010). Sustaining relationships: Working with strong feelings. In G. Ruch, D. Turney, \& A. Ward (Eds.), Relationship-based social work: Getting to the heart of practice (pp. 133-147). London: Jessica Kingsley Publishers.

Turney, D. (2012). A relationship-based approach to engaging involuntary clients: The contribution of recognition theory. Child \& Family Social Work, 17, 149-159.

Water, T. (2018). Ethical issues in participatory research with children and young people. In I. Coyne \& B. Carter (Eds.), Being participatory: Researching with children and young people: Coconstructing knowledge using creative techniques (pp. 37-56). Cham, Switzerland: Springer.

Williams, D., \& Lawlor, K. (2001). Obstacles to the professionalization of residential child care work. Irish Journal of Applied Social Studies, 2(3), 73-90.

Winter, K. (2010). The perspectives of young children in care about their circumstances and implications for social work practice. Child \& Family Social Work, 15, 186-195.

Winter, K. (2015) Supporting positive relationships for children and young people who have experience of care. Retrieved from https://www.iriss.org.uk/resources/insights/supportingpositive-relationships-children-young-people-experience-care

Zegers, M. A. M., Schuengel, C., Van IJzendoorn, M. H., \& Janssens, J. M. A. M. (2006). Attachment representations of institutionalized adolescents and their professional caregivers: Predicting the development of therapeutic relationships. The American Journal of Orthopsychiatry, 76, 325-334. 